\title{
EFEITOS DE ADITIVOS ACIDULANTES SOBRE DESENVOLVIMENTO E PRODUÇÃO DE AFLATOXINAS POR ASPERGILLUS FLAVUS E ASPERGILLUS PARASITICUS.
}

Sonia Sousa Melo Cavalcanti de Albuquerque
Departamento de Engeharia Química-CT/UFPE.

Maria Auxiliadora de Queiroz Cavalcanti Departamento de Micologia-CCB/UFPE.

Luis Antonio Borges Aguiar Departamento de Antibióticos-CCB/UFPE Av. Prof. Artur de Sá, S/N, Cidade Universitaria Recife (PE) Brasil CEP 50.741

Palabras clave: aditivos acidulantes, crecimiento, micotoxinas.

Key words: acidulants aditives, growth, mycotoxins

\section{RESUMO}

Foram testados os ácidos adipico $(0,5 \%, 1,0 \%$ e $2,0 \%)$, fosfórico $(0,03 \%, 0,10 \%$ e $0,20 \%)$, latico $(0,20 \%, 2,0 \%$ e $4,0 \%)$, málico $(0,20 \%, 1,0 \%$ e $2,0 \%)$, tartárico $(0,5 \%, 1,0 \%$ e $2,0 \%)$ e cítrico $(0,5 \%, 1,0 \%$ e 2,0\%). Estas concentraçôes foram escolhidas em funçâo da legislaçâo brasileira. Os ácidos que mais se destacaram como inibidores do crescimento e/ou da produçâo de aflatoxinas foram adípico, lático e málico, por inibir parcialmente $o$ crescimento e a produçao de aflatoxina.

\section{RESUMEN}

[Efecto de aditivos acidulantes sobre el desarrollo y producción de aflatoxinas por Aspergillus flavus y A. parasiticus.]

Se probaron los siguientes ácidos: adípico $(0,5 \%$, $1,0 \%$ y $2,0 \%)$, fosfórico $(0,03 \%, 0,10 \%$ y $0,20 \%)$, láctico $(0,20 \%, 2,0 \%$ y $4,0 \%)$, málico $(0,20 \%, 1,0 \%$ y $2,0 \%)$, tartárico $(0,5 \%, 1,0 \%$ y $2,0 \%)$ y cítrico $(0,5 \%, 1,0 \%$ y $2,0 \%)$. Las concentraciones fueron elegidas en función de la legislación brasileña. Los ácidos que más se destacaron como inhibidores del crecimiento $y / o$ productores de aflatoxina fueron adípico, málico y láctico por inhibir parcialmente el crecimiento y la producción de aflatoxina.

\section{SUMMARY}

[Effects of acidulants aditives on the growth and production of mycotaxins by Aspergillus navus and Aspergillus parasiticus]

The acidulants, adipic acid $(0,5 \%, 1,0 \%$ and $2,0 \%)$, fosforic acid $(0,03 \%, 0,10 \%$ and $0,20 \%)$, lactic acid $(0,20 \%, 2,0 \%$ and $4,0 \%)$, malic acid $(0,20 \%, 1,0 \%$ and $2,0 \%)$, tartaric acid $(0,5 \%, 1,0 \%$ and $2,0 \%)$ and citric acid $(0,5 \%, 1,0 \%$ and $2,0 \%)$. These concentrations were chosen on the basis of the brazilian law. The acids that showed to be most inhibitors were adipic, malic and lactic that partially inhibited the growth and/or aflatoxin production by the fungi. 


\section{INTRODUÇÃo}

Intencionalmente adicionados aos alimentos com finalidades diversas, os aditivos exercem um papel importante para os produtos industrializados, como por exemplo os acidulantes, usados em alimentos processados como ácidos orgânicos, inorgânicos ou seus sais. Tais substâncias sâo adicionadas aos alimentos nos quais sâo permitidos (bolos, geléias, sorvetes, maionese, vinhos, pós para pudins e refrescos, biscoitos, produtos de frutos, licores e outros), com a finalidade de controlar o $\mathrm{pH}$, conferir sabor e outras propriedades desejáveis no produto manufaturado (9). Fungos do grupo Aspergillus flavus encontram-se amplamente distribuídos, contribuindo para deterioraçâo de substratos produzindo aflatoxinas (3), que sâo metabólitos tóxicos carcinogênicos para vários tipos de animais (4). Neste trabalho procurou-se determinar a influência dos aditivos acidulantes testados sobre o desenvolvimento e/ou produçâo da toxina.

\section{MATERIAL E METODOS}

Foram utilizadas as seguintes amostras de fungos do grupo Aspergillus flavus: A. flavus NRRL 3251 e NRRL 5520 (produtoras das aflatoxinas B1 e B2 (2) e A. parasiticus NRRL 2999 e UNBF A12 (ambas produtoras de aflatoxinas B1, B2, G1 e G2, sendo que o UNBF A12 produz, ainda, ácido kójico) (5). As amostras com a sigla NRRL foram fornecidas pelo USDA "Northern Regional Research Laboratory", Peória, Illinois, USA e a com sigla UNBF pertence a coleçâo do Laboratório de Fitopatologia da Universidade de Brasília.

Os fungos utilizados como inóculo, nos experimentos, foram conservados em tubos com $10 \mathrm{ml}$ do meio Czapek-ágar (7), sendo transferidos para novos tubos a cada 6 meses.

$O$ inóculo foi preparado transferindo-se esporos das amostras mencionadas para placas de Petri contendo MDA (Meio Diferencial para Aspergillus) (1), logo após incubadas por 72 horas a $28^{\circ} \mathrm{C}$. Discos de ágar com $3 \mathrm{~mm}$ de diâmetro, contendo o micélio, foram transferidos para o centro de placas com MCA (Meio de Coco-Agar) (6) sendo a parte micelial colocada em contato direto com o meio de cultura. Os testes com os aditivos foram realizados neste meio, sendo os mesmos diluídos em água destilada esterilizada $(50 \mathrm{ml})$ e adicionados ao MCA após esterilizaçâo. As placas foram inocula- das e incubadas por 5 dias a $28^{\circ} \mathrm{C}$, sendo trés repetiçôes por tratamento. $O$ volume de água foi suficiente para completar $200 \mathrm{ml}$ de meio de cultu$\mathrm{ra}$, obtendo-se assim o volume final requerido ( 200 $\mathrm{ml}$ ). O crescimento dos fungos no quinto dia, foi avaliado pela medida de diâmetro das colônias. $\mathrm{O}$ grau de esporulaçâo e a pigmentaçâo das colônias foram observados macroscopicamente sob luz natural. A intensidade da fluorescência e a cor, sob ondas longas de luz ultravioleta. Para indicar o grau de esporulaçâo, forman utilizados algarismos que variaram de $0-4$, avaliados subjetivamente, comparando-se com a testemunha.

Os ácidos foram testados nas seguintes concentraçôes: ácido adípico $(0,5 \%, 1,0 \%$ e 2,0\%), ácido fosfórico $(0,03 \%, 0,10 \%$ e $0,20 \%)$, ácido lático $(0,20 \%, 2,0 \%$ e $4,0 \%)$, ácido málico $(0,20 \%, 1,0 \%$ e $2,0 \%)$, ácido tartárico $(0,5 \%, 1,0 \%$ e 2,0\%) e ácido cítrico $(0,5 \%, 1,0 \%$ e $2,0 \%)$.

Foram realizados experimentos paralelos com MCA acidificado com $\mathrm{HCl}$ a $20 \%$ com a finalidade de obter-se os mesmos $\mathrm{pH}$ determinados em presença dos aditivos, visando confirmar se o efeito inibitório deveu-se ao aditivo pelas suas propriedades químicas ou acidez excessiva promovida pelo mesmo.

\section{RESULTADOS E DISCUSSÃO}

O ácido adípico (Tabela 1) demonstrou ser um inihidor parcial do crescimento e produçâo de aflatoxina (AT), sendo mais efetivo para o Aspergillus parasiticus NRRL 2999 e Aspergillus flavus NRRL 5520, pois inibiu o crescimento e consegüentemente a produçâo de AT a $0,5 \%$ para o NRRL 2999 e a 1,0\% para o NRRL 5520. Nos experimentos realizados com o MCA acidificado, como $\mathrm{HCl}$ (Tabela 2), repetindo os $\mathrm{pH}$ correspondentes aos aferidos em presença do aditivo, observou-se a falta de crescimento das culturas, o que provavelmente nâo foi influenciado pela acidez no meio, desde que em pH 4,0, equivalente ao $\mathrm{pH}$ do MCA adicionado de 2,0\% do ácido adípico, houve crescimento e produçao de AT por A. parasiticus UNBF A12, A. flavus NRRL 3251 e NRRL 5520; entretanto o A. parasiticus NRRL 2999 nâo se desenvolveu neste pH. Embora nâo tenha inibido o crescimento e a produçâo de AT a 1,0\% limite máximo permitido para este aditivo em alimentos, em todas as amostras de fungos, é evidente á açâo do ácido adípico em fungos deste grupo; já o ácido fosfórico nâo exerceu controle no desenvolvimento e produçâo de $\mathrm{AT}$, embora tenha havido 
Tabela 1

Efeito do ácido adiplco no desenvolvimento e produgâo de Aflatoxinas por Aspergillus parasiticus (UNBF A 12 e NRRL 2999) e Aspergillus flavus (NRRL 5520 e NRRL 3251), em MCA após 5 dias de incubaçâ a $28^{\circ}$ C (a)

\begin{tabular}{|c|c|c|c|c|c|c|c|c|c|}
\hline AMOSTRA & $\begin{array}{l}\text { Concentrachio } \\
\text { do aditivo } \\
\text { (\%) }\end{array}$ & pH & $\begin{array}{c}\text { DUlumetro da } \\
\text { Colônia } \\
(\mathrm{mm})\end{array}$ & $\begin{array}{l}\text { Prgmentaçáto } \\
\text { do } \\
\text { micelio }\end{array}$ & $\begin{array}{l}\text { Grau de } \\
\text { esporalaçấ } \\
\text { (b) }\end{array}$ & Á Cor dos In & $\begin{array}{l}\text { Ioçâto d } \\
\text { Intensi- } \\
\text { dade (c) }\end{array}$ & de AT $\mathrm{Cor}$ & \\
\hline $\begin{array}{l}\text { A. parasiticus } \\
\text { UNBF A } 12\end{array}$ & $\begin{array}{l}0 \\
0,5 \\
1,0 \\
2,0\end{array}$ & $\begin{array}{l}7,0 \\
5,5 \\
5,0 \\
4,0\end{array}$ & $\begin{array}{c}42 \\
35 \\
35 \\
0\end{array}$ & $\begin{array}{c}\text { alaranjado } \\
\text { alaranjado } \\
\text { alaranjado }\end{array}$ & $\begin{array}{ll}3 & v \\
0 & \\
0 & \\
0 & \end{array}$ & $\begin{array}{c}\text { verde amarelo } \\
- \\
-\end{array}$ & $\begin{array}{l}4 \\
3 \\
3 \\
0\end{array}$ & $\begin{array}{c}\text { azul violeta } \\
\text { azul violeta } \\
\text { azul violeta } \\
\text { - }\end{array}$ & \\
\hline $\begin{array}{l}\text { A. parasiticus } \\
\text { NRRL } 2999\end{array}$ & $\begin{array}{l}0 \\
0,5 \\
1,0 \\
2,0\end{array}$ & $\begin{array}{l}7,0 \\
5,5 \\
5,0 \\
4,0\end{array}$ & $\begin{array}{c}42 \\
0 \\
0 \\
0\end{array}$ & $\begin{array}{c}\text { alaranjado } \\
- \\
- \\
-\end{array}$ & $\begin{array}{l}3 \\
0 \\
0 \\
0\end{array}$ & $\begin{array}{c}\text { verde branco } \\
- \\
- \\
-\end{array}$ & $\begin{array}{l}3 \\
0 \\
0 \\
0\end{array}$ & $\begin{array}{c}\text { azul violeta } \\
- \\
- \\
-\end{array}$ & \\
\hline $\begin{array}{l}\text { A. navus } \\
\text { NRRL } 5520\end{array}$ & $\begin{array}{l}0 \\
0,5 \\
1,0 \\
2,0\end{array}$ & $\begin{array}{l}7,0 \\
5,5 \\
5,0 \\
4,0\end{array}$ & $\begin{array}{c}41 \\
30 \\
0 \\
0\end{array}$ & $\begin{array}{c}\text { alaranjado } \\
\text { alaranjado } \\
- \\
.\end{array}$ & $\begin{array}{l}3 \\
2 \\
0 \\
0\end{array}$ & $\begin{array}{c}\text { verde } \\
\text { verde } \\
- \\
-\end{array}$ & $\begin{array}{l}3 \\
3 \\
0 \\
0\end{array}$ & $\begin{array}{c}\text { azul violeta } \\
\text { azul violeta } \\
- \\
-\end{array}$ & \\
\hline $\begin{array}{l}\text { A. flavus } \\
\text { NRRL } 3251\end{array}$ & $\begin{array}{c}0 \\
0,5 \\
1,0 \\
2,0\end{array}$ & $\begin{array}{l}7,0 \\
5,5 \\
5,0 \\
4,0\end{array}$ & $\begin{array}{c}46 \\
30 \\
23 \\
0\end{array}$ & $\begin{array}{c}\text { alaranjado } \\
\text { alaranjado } \\
\text { alaranjado }\end{array}$ & $\begin{array}{ll}3 & \mathrm{~m} \\
2 & \mathrm{~m} \\
2 & \mathrm{~m} \\
0 & \end{array}$ & $\begin{array}{l}\text { marrom branco } \\
\text { marrom branco } \\
\text { marrom branco }\end{array}$ & $\begin{array}{l}0 \\
0 \\
0 \\
0 \\
0 \\
\end{array}$ & $\begin{array}{l}3 \\
3 \\
3 \\
-\end{array}$ & $\begin{array}{l}\text { azul violeta } \\
\text { azul violeta } \\
\text { azul violeta }\end{array}$ \\
\hline
\end{tabular}

(a) Média de três repetiçóes.

b) Grau de esporulaçâo: de 0 (sem esporulaçâo) a 3 (forte).

(c) Intensidade de fluorescência: de 0 (sem fluorescencia) a 4 (muito intensa).

Tabela 2

Aspergillus parasiticus (UNBF A 12 e NRRL 2999) e Aspergillus flavus (NRRL 3251 e NRRL 5520) desenvolvidos em MCA acidificado com HCl, após 5 dias de incubaçâo a $28^{2} \mathrm{C}$

\begin{tabular}{|c|c|c|c|c|c|c|c|c|}
\hline AMOSTRA & & $\begin{array}{l}\text { pH } \\
\text { (b) }\end{array}$ & $\begin{array}{l}\text { Difimetro da } \\
\text { colónia } \\
\text { (mm) }\end{array}$ & $\begin{array}{c}\text { Pigmentaçâo } \\
\text { do } \\
\text { micelio }\end{array}$ & $\begin{array}{l}\text { Graa de } \\
\text { espornlaçấo } \\
\text { (c) }\end{array}$ & 3o Cor dos & $\begin{array}{l}\text { Iuçấo d } \\
\text { Intensi- } \\
\text { lade (d) }\end{array}$ & Cor \\
\hline $\begin{array}{l}\text { A. parasiticus } \\
\text { UNBF A } 12\end{array}$ & & $\begin{array}{l}7,0 \\
5,5 \\
5,0 \\
4,0\end{array}$ & $\begin{array}{l}45 \\
40 \\
43 \\
40\end{array}$ & $\begin{array}{l}\text { alaranjado } \\
\text { alaranjado } \\
\text { alaranjado } \\
\text { alaranjado }\end{array}$ & $\begin{array}{ll}3 & \mathrm{v} \\
0 & \\
0 & \\
0 & \end{array}$ & $\begin{array}{c}\text { verde amarelo } \\
- \\
- \\
-\end{array}$ & $\begin{array}{l}4 \\
4 \\
4 \\
4\end{array}$ & $\begin{array}{l}\text { azul violeta } \\
\text { azul violeta } \\
\text { azul violeta } \\
\text { azul violeta }\end{array}$ \\
\hline $\begin{array}{l}\text { A. parasiticus } \\
\text { NRRL } 2999\end{array}$ & & $\begin{array}{l}7,0 \\
5,5 \\
5,0 \\
4,0\end{array}$ & $\begin{array}{c}40 \\
36 \\
35 \\
0\end{array}$ & $\begin{array}{c}\text { alaranjado } \\
\text { alaranjado } \\
\text { alaranjado } \\
\end{array}$ & $\begin{array}{l}3 \\
2 \\
2 \\
0\end{array}$ & $\begin{array}{l}\text { verde } \\
\text { verde } \\
\text { verde } \\
\text { verde }\end{array}$ & $\begin{array}{l}3 \\
3 \\
2 \\
0\end{array}$ & $\begin{array}{c}\text { azul violeta } \\
\text { azul violeta } \\
\text { azul violeta } \\
\text { - }\end{array}$ \\
\hline $\begin{array}{l}\text { A. flavus } \\
\text { NRRL } 5520\end{array}$ & & $\begin{array}{l}7,0 \\
5,5 \\
5,0 \\
4,0\end{array}$ & $\begin{array}{l}40 \\
35 \\
35 \\
30\end{array}$ & $\begin{array}{l}\text { alaranjado } \\
\text { alaranjado } \\
\text { alaranjado } \\
\text { alaranjado }\end{array}$ & $\begin{array}{l}3 \\
2 \\
3 \\
1\end{array}$ & $\begin{array}{l}\text { verde } \\
\text { verde } \\
\text { verde } \\
\text { verde }\end{array}$ & $\begin{array}{l}3 \\
3 \\
3 \\
3\end{array}$ & $\begin{array}{l}\text { azul violeta } \\
\text { azul violeta } \\
\text { azul violeta } \\
\text { azul violeta }\end{array}$ \\
\hline $\begin{array}{l}\text { A. favus } \\
\text { NRRL } 3251\end{array}$ & ' & $\begin{array}{l}7,0 \\
5,5 \\
5,0 \\
4,0\end{array}$ & $\begin{array}{l}43 \\
41 \\
41 \\
27\end{array}$ & $\begin{array}{l}\text { alaranjado } \\
\text { alaranjado } \\
\text { alaranjado } \\
\text { alaranjado }\end{array}$ & $\begin{array}{l}3 \\
2 \\
2 \\
1\end{array}$ & $\begin{array}{l}\text { marrom } \\
\text { marrom } \\
\text { marrom } \\
\text { marrom }\end{array}$ & $\begin{array}{l}3 \\
3 \\
3 \\
3\end{array}$ & $\begin{array}{l}\text { azul violeta } \\
\text { azul violeta } \\
\text { azul violeta } \\
\text { azul violeta }\end{array}$ \\
\hline
\end{tabular}

(a) Média de três repetiçôes.

(b) Corresponde aos mesmos $\mathrm{pH}$ do experimento com ácido adípico.

(b) Grau de esporulaçâo: de 0 (sem esporulaçâo) a 4 (forte).

(c) Intensidade de fluorescência: de 0 (sem fluorescencia) a 4 (muito intensa). 
Tabela 3

Efeito do ácido fosfórico no desenvolvimento e produçâo de aflatoxinas por Aspergillus parasiticus (UNBF A 12 e NRRL 2999) e Aspergillus flavus (NRRL 5520 e NRRL 3251), em MCA após 5 dias de incubaçâo a $28^{\circ}$ C

\begin{tabular}{|c|c|c|c|c|c|c|c|c|}
\hline AMOSTRA & $\begin{array}{c}\text { Concentraçâo } \\
\text { do aditivo } \\
(\%)\end{array}$ & $\begin{array}{l}\text { Uíimetro da } \\
\text { colônia } \\
(\mathrm{mm})\end{array}$ & $\begin{array}{c}\text { Pigmentaçáo } \\
\text { do } \\
\text { micelio }\end{array}$ & $\begin{array}{l}\text { Grau de } \\
\text { esporulaçâo } \\
\text { (b) }\end{array}$ & $\begin{array}{l}\text { Cor dos } \\
\text { esporos }\end{array}$ & $\begin{array}{r}P \\
\text { Intensi- } \\
\text { dade (c) }\end{array}$ & $\begin{array}{l}\text { Produçấo de AT } \\
\text { Cor } \\
\text { at }\end{array}$ & \\
\hline $\begin{array}{l}\text { A. parasiticus } \\
\text { UNBF A } 12\end{array}$ & $\begin{array}{c}0 \\
0.03 \\
0,10 \\
0,20\end{array}$ & $\begin{array}{l}49 \\
49 \\
39 \\
40\end{array}$ & $\begin{array}{l}\text { alaranjado } \\
\text { alaranjado } \\
\text { alaranjado } \\
\text { alaranjado }\end{array}$ & $\begin{array}{ll}3 & \text { ve } \\
3 & \text { ve } \\
2 & \text { ve } \\
1 & \text { ve }\end{array}$ & $\begin{array}{l}\text { verde amarelo } \\
\text { verde amarelo } \\
\text { verde amarelo } \\
\text { verde amarelo }\end{array}$ & $\begin{array}{lll}0 & 4 & \\
0 & 4 & \\
0 & 4 & \\
0 & 4 & \end{array}$ & $\begin{array}{l}\text { azul violeta } \\
\text { azul violeta } \\
\text { azul violeta } \\
\text { azul violeta }\end{array}$ & \\
\hline $\begin{array}{l}\text { A. parasiticus } \\
\text { NRRL } 2999\end{array}$ & $\begin{array}{c}0 \\
0,0,3 \\
0,10 \\
0,20\end{array}$ & $\begin{array}{l}47 \\
43 \\
43 \\
42\end{array}$ & $\begin{array}{l}\text { alaranjado } \\
\text { alaranjado } \\
\text { alaranjado } \\
\text { alaranjado }\end{array}$ & $\begin{array}{l}3 \\
3 \\
3 \\
2\end{array}$ & $\begin{array}{l}\text { verde } \\
\text { verde } \\
\text { verde } \\
\text { verde }\end{array}$ & $\begin{array}{l}4 \\
4 \\
4 \\
4\end{array}$ & $\begin{array}{l}\text { azul violeta } \\
\text { azul violeta } \\
\text { azul violeta } \\
\text { azul violeta }\end{array}$ & \\
\hline $\begin{array}{l}\text { A. flavus } \\
\text { NRRL } 5520\end{array}$ & $\begin{array}{c}0 \\
0,03 \\
0,10 \\
0,20\end{array}$ & $\begin{array}{l}43 \\
41 \\
42 \\
35\end{array}$ & $\begin{array}{l}\text { alaranjado } \\
\text { alaranjado } \\
\text { alaranjado } \\
\text { alaranjado }\end{array}$ & $\begin{array}{l}3 \\
3 \\
3 \\
2\end{array}$ & $\begin{array}{l}\text { verde } \\
\text { verde } \\
\text { verde } \\
\text { verde }\end{array}$ & $\begin{array}{l}3 \\
3 \\
3\end{array}$ & $\begin{array}{l}\text { azul violeta } \\
\text { azul violeta } \\
\text { azul violeta } \\
\text { azul violeta }\end{array}$ & \\
\hline $\begin{array}{l}\text { A. flavus } \\
\text { NRRL } 3251\end{array}$ & $\begin{array}{c}0 \\
0,03 \\
0,10 \\
0,20\end{array}$ & $\begin{array}{l}45 \\
45 \\
43 \\
37\end{array}$ & $\begin{array}{l}\text { alaranjado } \\
\text { alaranjado } \\
\text { alaranjado } \\
\text { alaranjado }\end{array}$ & $\begin{array}{l}3 \\
3 \\
3 \\
3\end{array}$ & $\begin{array}{l}\text { marrom } \\
\text { marrom } \\
\text { marrom } \\
\text { marrom }\end{array}$ & $\begin{array}{l}3 \\
3 \\
3 \\
3\end{array}$ & $\begin{array}{l}\text { azul violeta } \\
\text { azul violeta } \\
\text { azul violeta } \\
\text { azul violeta }\end{array}$ & \\
\hline
\end{tabular}

(a) Média de três repetiçôes.
(b) Grau de esporulaçâo: de 0 (sem esporulaçâo) a 3 (forte).
(c) Intensidade de fluorescência: de 0 (sem fluorescencia) a 4 (muito intensa).

Tabela 4

Efeito do ácido lático no desenvolvimento e produçâo de Aflatoxinas por Aspergillus parasiticus (UNBF A 12 e NRRL 2999) e Aspergillus flavus (NRRL 5520 e NRRL 3251), em MCA após 5 dias de incubaçâo a $28^{\circ} \mathrm{C}^{\text {(a) }}$

\begin{tabular}{|c|c|c|c|c|c|c|c|c|c|}
\hline AMOSTRA & $\begin{array}{c}\text { Concentraçâo } \\
\text { do aditivo } \\
\mid \text { Fel }\end{array}$ & $\mathrm{pH}$ & $\begin{array}{l}\text { Diâmetro da } \\
\text { colônia } \\
\text { |mm| }\end{array}$ & $\begin{array}{c}\text { Pigmentaçáo } \\
\text { do } \\
\text { micelio }\end{array}$ & $\begin{array}{l}\text { Grau de } \\
\text { esporulaçâo } \\
\text { (b) }\end{array}$ & $\begin{array}{l}\text { Cur dos } \\
\text { esporos }\end{array}$ & $\begin{array}{l}\text { Intensi- } \\
\text { dade (c) }\end{array}$ & Cor & \\
\hline $\begin{array}{l}\text { A. parasiticus } \\
\text { UNBF A } 12\end{array}$ & $\begin{array}{c}0 \\
0,20 \\
2,0 \\
4,0\end{array}$ & $\begin{array}{l}7,0 \\
5,5 \\
4,0 \\
3,0\end{array}$ & $\begin{array}{c}50 \\
43 \\
30 \\
5\end{array}$ & $\begin{array}{l}\text { alaranjado } \\
\text { alaranjado } \\
\text { alaranjado } \\
\text { alaranjado }\end{array}$ & $\begin{array}{ll}3 & \text { ve } \\
1 & v e \\
1 & v e \\
1 & v e\end{array}$ & $\begin{array}{l}\text { verde amarelo } \\
\text { verde amarelo } \\
\text { verde amarelo } \\
\text { verde amarelo }\end{array}$ & $\begin{array}{l}3 \\
3 \\
2 \\
0\end{array}$ & $\begin{array}{c}\text { azul violeta } \\
\text { azul violeta } \\
\text { azul violeta } \\
\text { - }\end{array}$ & \\
\hline $\begin{array}{l}\text { A. parasiticus } \\
\text { NRRL } 2999\end{array}$ & $\begin{array}{c}0 \\
0,20 \\
2,0 \\
4,0\end{array}$ & $\begin{array}{l}7.0 \\
5.5 \\
4.0 \\
3.0\end{array}$ & $\begin{array}{l}53 \\
45 \\
41 \\
12\end{array}$ & $\begin{array}{l}\text { alaranjado } \\
\text { alaranjado } \\
\text { alaranjado } \\
\text { alaranjado }\end{array}$ & $\begin{array}{l}3 \\
1 \\
1 \\
1\end{array}$ & $\begin{array}{l}\text { verde } \\
\text { verde } \\
\text { verde } \\
\text { verde }\end{array}$ & $\begin{array}{l}3 \\
3 \\
3 \\
2\end{array}$ & $\begin{array}{l}\text { azul violeta } \\
\text { azul violeta } \\
\text { azul violeta } \\
\text { azul violeta }\end{array}$ & \\
\hline $\begin{array}{l}\text { A. havus } \\
\text { NRRL } 5520\end{array}$ & $\begin{array}{c}0 \\
0,20 \\
2,0 \\
4,0\end{array}$ & $\begin{array}{l}7,0 \\
5,5 \\
4,0 \\
3,0\end{array}$ & $\begin{array}{l}46 \\
36 \\
15 \\
0\end{array}$ & $\begin{array}{l}\text { alaranjado } \\
\text { alaranjado } \\
\text { alaranjado } \\
\text { alaranjado }\end{array}$ & $\begin{array}{l}3 \\
2 \\
2 \\
0\end{array}$ & $\begin{array}{l}\text { verde } \\
\text { verde } \\
\text { verde } \\
\text { verde }\end{array}$ & $\begin{array}{l}3 \\
3 \\
1 \\
0\end{array}$ & $\begin{array}{c}\text { azul violeta } \\
\text { azul violeta } \\
\text { azul violeta } \\
\text { - }\end{array}$ & \\
\hline $\begin{array}{l}\text { A. flavus } \\
\text { NRRL. } 3251\end{array}$ & $\begin{array}{c}0 \\
0.20 \\
2,0 \\
4,0\end{array}$ & $\begin{array}{l}7,0 \\
5,5 \\
4,0 \\
3,0\end{array}$ & $\begin{array}{c}53 \\
43 \\
19 \\
7\end{array}$ & $\begin{array}{l}\text { alaranjado } \\
\text { alaranjado } \\
\text { alaranjado } \\
\text { alaranjado }\end{array}$ & $\begin{array}{l}3 \\
2 \\
1 \\
1\end{array}$ & $\begin{array}{l}\text { marrom } \\
\text { marrom } \\
\text { marrom } \\
\text { marrom }\end{array}$ & $\begin{array}{l}3 \\
3 \\
3 \\
0\end{array}$ & $\begin{array}{l}\text { azul violeta } \\
\text { azul violeta } \\
\text { azul violeta } \\
\text { azul violeta }\end{array}$ & \\
\hline
\end{tabular}

(a) Média de três repetiçóes.

(b) Grau de esporulaçâo: de 0 (sem esporulaçâo) a 3 (forte)

(c) Intensidade de fluorescência: de 0 (sem fluorescencia) a 4 (muito intensa). 


\section{Tabela 5}

Efeito do ácido málico no desenvolvimento e produçâo de Aflatoxinas por Aspergillus parasiticus (UNBF A 12 e NRRL 2999) e Aspergillus favus (NRRL 5520 e NRRL 3251), em MCA após 5 dias de incubaçâo a $28^{2}$ C

\begin{tabular}{|c|c|c|c|c|c|c|c|c|}
\hline AMOSTRA & $\begin{array}{c}\begin{array}{c}\text { Concentraçâo } \\
\text { do aditivo } \\
\left(\Psi_{0}\right)\end{array} \\
0 \\
020\end{array}$ & $\begin{array}{l}\text { pH } \\
7,0\end{array}$ & $\begin{array}{c}\begin{array}{c}\text { Diâmetro da } \\
\text { colônia } \\
\text { (mm) }\end{array} \\
54 \\
50\end{array}$ & $\begin{array}{c}\begin{array}{c}\text { Pigmentaçâo } \\
\text { do } \\
\text { micelio }\end{array} \\
\text { alaranjado } \\
\text { alaranjado }\end{array}$ & \multicolumn{3}{|c|}{ 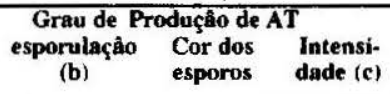 } & Cor \\
\hline $\begin{array}{l}\text { A. parasiticus } \\
\text { UNBF A } 12\end{array}$ & $\begin{array}{c}0 \\
0,20 \\
1,0 \\
2,0\end{array}$ & $\begin{array}{l}7,0 \\
4,5 \\
3,0 \\
2,0\end{array}$ & $\begin{array}{c}54 \\
50 \\
0 \\
0\end{array}$ & $\begin{array}{c}\text { alaranjado } \\
\text { alaranjado } \\
-\end{array}$ & $\begin{array}{ll}3 & v \\
1 & v \\
0 & \\
0 & \end{array}$ & $\begin{array}{c}\text { verde amarelo } \\
\text { verde amarelo } \\
\text { - } \\
\text { - }\end{array}$ & $\begin{array}{ll}0 & 4 \\
0 & 4 \\
& 0 \\
& 0\end{array}$ & $\begin{array}{c}\text { azul violeta } \\
\text { azul violeta } \\
\text { - } \\
\text { - }\end{array}$ \\
\hline $\begin{array}{l}\text { A. parasiticus } \\
\text { NRRL } 2999\end{array}$ & $\begin{array}{c}0 \\
0,20 \\
1,0 \\
2,0\end{array}$ & $\begin{array}{l}7,0 \\
4,5 \\
3,0 \\
2,0\end{array}$ & $\begin{array}{c}52 \\
45 \\
0 \\
0\end{array}$ & $\begin{array}{c}\text { alaranjado } \\
\text { alaranjado } \\
- \\
-\end{array}$ & $\begin{array}{l}3 \\
1 \\
0 \\
0\end{array}$ & $\begin{array}{c}\text { verde } \\
\text { verde } \\
- \\
-\end{array}$ & $\begin{array}{l}3 \\
3 \\
0 \\
0\end{array}$ & $\begin{array}{c}\text { azul violeta } \\
\text { azul violeta } \\
\text { - } \\
\text { - }\end{array}$ \\
\hline $\begin{array}{l}\text { A. flavus } \\
\text { NRRL } 5520\end{array}$ & $\begin{array}{c}0 \\
0,20 \\
1,0 \\
2,0\end{array}$ & $\begin{array}{l}7,0 \\
4,5 \\
3,0 \\
2,0\end{array}$ & $\begin{array}{c}50 \\
42 \\
0 \\
0\end{array}$ & $\begin{array}{c}\text { alaranjado } \\
\text { alaranjado } \\
-\end{array}$ & $\begin{array}{l}3 \\
1 \\
0 \\
0\end{array}$ & $\begin{array}{c}\text { verde } \\
\text { verde } \\
- \\
-\end{array}$ & $\begin{array}{l}3 \\
3 \\
0 \\
0\end{array}$ & $\begin{array}{c}\text { azul violeta } \\
\text { azul violeta } \\
- \\
-\end{array}$ \\
\hline $\begin{array}{l}\text { A. flavus } \\
\text { NRRL } 3251\end{array}$ & $\begin{array}{c}0 \\
0,20 \\
1,0 \\
2,0\end{array}$ & $\begin{array}{l}7,0 \\
4,5 \\
3,0 \\
2,0\end{array}$ & $\begin{array}{c}55 \\
42 \\
0 \\
0\end{array}$ & $\begin{array}{c}\text { alaranjado } \\
\text { alaranjado } \\
- \\
-\end{array}$ & $\begin{array}{l}3 \\
2 \\
0 \\
0\end{array}$ & $\begin{array}{c}\text { marron } \\
\text { marron } \\
- \\
-\end{array}$ & $\begin{array}{l}3 \\
3 \\
0 \\
0\end{array}$ & $\begin{array}{c}\text { azul violeta } \\
\text { azul violeta } \\
- \\
-\end{array}$ \\
\hline
\end{tabular}

(a) Média de três repetiçôes.

b) Grau de esporulaçâo: de 0 (sem fluorescência) a 4 (muito intenso).

(c) Intensidade de fluorescência: de 0 (sem fluorescencia) a 4 (muito intensa).

\section{Tabela 6}

Aspergillus parasiticus (UNBF A 12 e NRRL 2999) e Aspergillus flavus (NRRL 3251 e NRRL 5520) desenvolvidos em MCA acidificado com $\mathrm{HCl}$, após 5 dias de incubaçâo a $28^{\circ} \mathrm{C}$

\begin{tabular}{|c|c|c|c|c|c|c|c|c|}
\hline \multicolumn{2}{|l|}{ AMOSTRA } & $\frac{\mathbf{p H}^{(\mathbf{b})}}{7,0}$ & $\begin{array}{c}\begin{array}{c}\text { Diâmetro da } \\
\text { colônia } \\
\text { (mm) }\end{array} \\
50\end{array}$ & $\begin{array}{c}\begin{array}{c}\text { Pigmentaçấo } \\
\text { do } \\
\text { micelio }\end{array} \\
\text { alaranjado }\end{array}$ & $\begin{array}{c}\text { Grau de } \\
\text { esporulaçâo } \\
\text { (c) }\end{array}$ & \multicolumn{3}{|c|}{$\begin{array}{lll} & \text { Produçấo de AT } \\
\text { Cor dos } & \text { Intensi- } \\
\text { esporos } & \text { dade } & \text { (d) }\end{array}$ Cor } \\
\hline $\begin{array}{l}\text { A. parasiticus } \\
\text { UNBF A } 12\end{array}$ & & $\begin{array}{l}7,0 \\
4,5 \\
3,0 \\
2,0\end{array}$ & $\begin{array}{c}50 \\
48 \\
25 \\
0\end{array}$ & $\begin{array}{c}\text { alaranjado } \\
\text { alaranjado } \\
\text { alaranjado }\end{array}$ & $\begin{array}{ll}3 & \text { ve } \\
1 & \text { ve } \\
0 & \\
0 & \end{array}$ & $\begin{array}{c}\text { erde amarelo } \\
\text { erde amarelo } \\
\text { - } \\
\text { - }\end{array}$ & \begin{tabular}{|l|l}
0 & 4 \\
0 & 4 \\
& 2 \\
& 0
\end{tabular} & $\begin{array}{l}\text { azul violeta } \\
\text { azul violeta } \\
\text { azul violeta } \\
\text { azul violeta }\end{array}$ \\
\hline $\begin{array}{l}\text { A. parasiticus } \\
\text { NRRL } 2999\end{array}$ & & $\begin{array}{l}7,0 \\
4,5 \\
3,0 \\
2,0\end{array}$ & $\begin{array}{c}49 \\
47 \\
22 \\
0\end{array}$ & $\begin{array}{c}\text { alaranjado } \\
\text { alaranjado } \\
\text { alaranjado }\end{array}$ & $\begin{array}{l}3 \\
2 \\
0 \\
0\end{array}$ & $\begin{array}{c}\text { verde } \\
\text { verde } \\
- \\
-\end{array}$ & $\begin{array}{l}3 \\
3 \\
0 \\
0\end{array}$ & $\begin{array}{l}\text { azul violeta } \\
\text { azul violeta } \\
\text { azul violeta } \\
\text { azul violeta }\end{array}$ \\
\hline $\begin{array}{l}\text { A. flavus } \\
\text { NRRL } 5520\end{array}$ & & $\begin{array}{l}7,0 \\
4,5 \\
3,0 \\
2,0\end{array}$ & $\begin{array}{l}49 \\
37 \\
0 \\
0\end{array}$ & $\begin{array}{c}\text { alaranjado } \\
\text { alaranjado } \\
- \\
-\end{array}$ & $\begin{array}{l}3 \\
2 \\
0 \\
0\end{array}$ & $\begin{array}{c}\text { verde } \\
\text { verde } \\
- \\
-\end{array}$ & $\begin{array}{l}3 \\
2 \\
0 \\
0\end{array}$ & $\begin{array}{l}\text { azul violeta } \\
\text { azul violeta } \\
\text { azul violeta } \\
\text { azul violeta }\end{array}$ \\
\hline $\begin{array}{l}\text { A. flavus } \\
\text { NRRL } 3251\end{array}$ & t & $\begin{array}{l}7,0 \\
4,5 \\
3,0 \\
2,0\end{array}$ & $\begin{array}{c}53 \\
45 \\
0 \\
0\end{array}$ & $\begin{array}{c}\text { alaranjado } \\
\text { alaranjado } \\
- \\
-\end{array}$ & $\begin{array}{l}3 \\
2 \\
0 \\
0\end{array}$ & $\begin{array}{c}\text { marrom } \\
\text { marrom } \\
. \\
.\end{array}$ & $\begin{array}{l}3 \\
3 \\
0 \\
0\end{array}$ & $\begin{array}{c}\text { azul violeta } \\
\text { azul violeta } \\
- \\
-\end{array}$ \\
\hline
\end{tabular}

(a) Média de três repetiçôes.

(b) Corresponde aos mesmos pH do experimento com ácido mático.

c) Grau de esporulaçâo: de 0 (sem esporulaçâo) a 3 (forte).

(d) Intensidade de fluorescência: de 0 (sem fluorescencia) a 4 (muito intensa). 
Tabela 7

Efeito do ácido Tartárico no desenvolvimento e produçáo de Aflatoxinas por Aspergillus parasiticus (UNBF A 12 e NRRL 2999) e Aspergillus flavus (NRRL 5520 e NRRL 3251), em MCA após 5 dias de incubaçáo a $28^{2} C^{\text {(a) }}$

\begin{tabular}{|c|c|c|c|c|c|c|c|c|c|}
\hline AMOSTRA & $\begin{array}{l}\text { Concentraçào } \\
\text { do aditivo } \\
(\%)\end{array}$ & $\mathrm{pH}$ & $\begin{array}{l}\text { Diâmetro da } \\
\text { colônia } \\
\text { (mm) }\end{array}$ & $\begin{array}{c}\text { Pigmentaçâo } \\
\text { do } \\
\text { micelio }\end{array}$ & $\begin{array}{l}\text { Grau de } \\
\text { esponulaçâo } \\
\text { (b) }\end{array}$ & $\begin{array}{l}\text { Produ } \\
\text { esporos In }\end{array}$ & $\begin{array}{l}\text { çâo de } \\
\text { Itensi- } \\
\text { Ide (c) }\end{array}$ & Cor & \\
\hline $\begin{array}{l}\text { A. parasiticus } \\
\text { UNBF A } 12\end{array}$ & $\begin{array}{c}0 \\
0,5 \\
1,0 \\
2,0\end{array}$ & $\begin{array}{l}7,0 \\
4,0 \\
3,5 \\
3,0\end{array}$ & $\begin{array}{c}47 \\
45 \\
42 \\
0\end{array}$ & $\begin{array}{l}\text { alaranjado } \\
\text { alaranjado } \\
\text { alaranjado }\end{array}$ & $\begin{array}{ll}3 & \text { ve } \\
0 & \text { ve } \\
0 & \text { ve } \\
0 & \text { ve }\end{array}$ & $\begin{array}{l}\text { verde amarelo } \\
\text { verde amarelo } \\
\text { verde amarelo } \\
\text { verde amarelo }\end{array}$ & $\begin{array}{l}4 \\
3 \\
3 \\
0\end{array}$ & $\begin{array}{l}\text { azul violeta } \\
\text { azul violeta } \\
\text { azul violeta } \\
\text { azul violeta }\end{array}$ & . \\
\hline $\begin{array}{l}\text { A. parasiticus } \\
\text { NRRL } 2999\end{array}$ & $\begin{array}{l}0 \\
0,5 \\
1,0 \\
2,0\end{array}$ & $\begin{array}{l}7,0 \\
4,0 \\
3,5 \\
3,0\end{array}$ & $\begin{array}{l}48 \\
28 \\
17 \\
0\end{array}$ & $\begin{array}{c}\text { alaranjado } \\
\text { alaranjado } \\
\text { alaranjado } \\
-\end{array}$ & $\begin{array}{l}3 \\
0 \\
0 \\
0\end{array}$ & $\begin{array}{l}\text { verde } \\
\text { verde } \\
\text { verde } \\
\text { verde }\end{array}$ & $\begin{array}{l}3 \\
3 \\
3 \\
0\end{array}$ & $\begin{array}{l}\text { azul violeta } \\
\text { azul violeta } \\
\text { azul violeta } \\
\text { azul violeta }\end{array}$ & \\
\hline $\begin{array}{l}\text { A. flavus } \\
\text { NRRL } 5520\end{array}$ & $\begin{array}{c}0 \\
0,5 \\
1,0 \\
2,0\end{array}$ & $\begin{array}{l}7,0 \\
4,0 \\
3,5 \\
3,0\end{array}$ & $\begin{array}{l}45 \\
30 \\
25 \\
0\end{array}$ & $\begin{array}{c}\text { alaranjado } \\
\text { alaranjado } \\
\text { alaranjado }\end{array}$ & $\begin{array}{l}3 \\
2 \\
2 \\
0\end{array}$ & $\begin{array}{l}\text { verde } \\
\text { verde } \\
\text { verde } \\
\text { verde }\end{array}$ & $\begin{array}{l}3 \\
3 \\
3 \\
0\end{array}$ & $\begin{array}{l}\text { azul violeta } \\
\text { azul violeta } \\
\text { azul violeta } \\
\text { azul violeta }\end{array}$ & \\
\hline
\end{tabular}

(a) Média de três repetiçôes.

(b) Grau de esporulaçâo: de 0 (sem esporulaçâo) a 3 (forte)

(c) Intensidade de fluorescência: de 0 (sem fluorescencia) a 4 (muito intensa)

Tabela 8

Efeito do ácido cítrico no desenvolvimento e produçâo de Aflatoxinas por Aspergillus parasiticus (UNBF A 12 e NRRL 2999) e Aspergillus flavus (NRRL 5520 e NRRL 3251), em MCA após 5 dias de incubaçâo a $28^{\circ} \mathrm{C}$

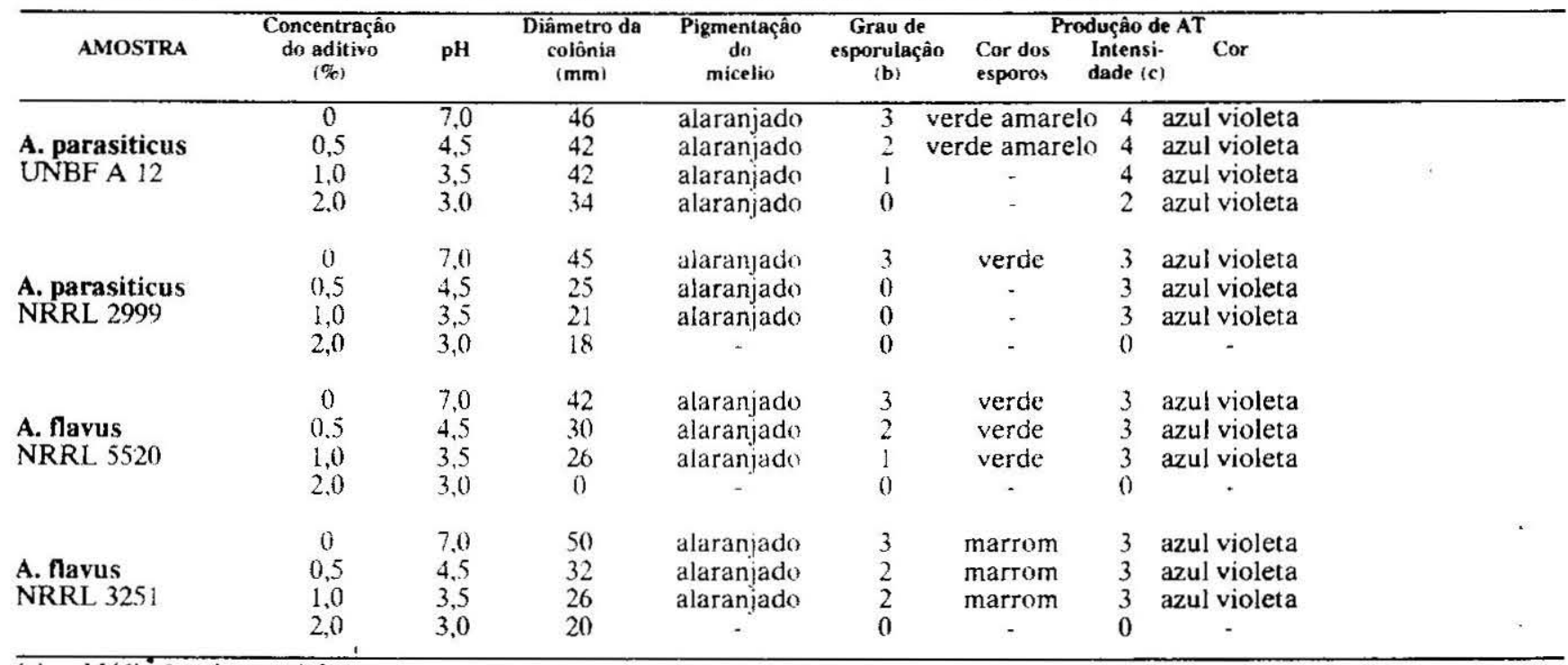

(a) Média de três repetiçôes

b) Grau de esporulaçâo: de 0 (sem esporulaşâo) a 3 (forte)

(c) Intensidade de fluorescência: de 0 (sem fluorescencia) a 4 (muito intensa). 
uma pequena inibiçâo no diâmetro das colônias a $0,20 \%$ do aditivo (Tabela 3). Con relaçâo ao ácido lático, observou-se que o mesmo provocou disminuiçâo sensível no crescimento dos fungos e menos acentuada na produçâo de AT (Tabela 4). Em meio acidificado com $\mathrm{HCl}$ a $20 \%$, o crescimento foi maior e a produçâo de AT também, o que sugere que o ácido lático tem atuaçâo parcial como inibidor dos fungos, resultante das suas propriedades químicas. Reiss (8), testando a açâo do ácido lático sobre o crescimento e produçâo de AT por Aspergillus parasiticus, adicionou $0,75 \%$ do ácido à massa do pâo de trigo e constatou inibiçâo de cresciumento e da produçâo de AT. Comparandose os resultados obtidos neste trabalho com os de Reiss, verificamos que, dependendo do substrato e das condiçôes empregadas, este ácido pode ser eficiente ou ineficaz para fungos toxigênicos.

$\mathrm{O}$ ácido málico inibiu o crescimento dos fungos a 1,0\%, limite máximo permitido para o mesmo (Tabela 5). Em meio acidificado com $\mathrm{HCl}$ a $20 \%$, os resultados foram praticamente os mesmos entretando este resultados devem ser considerados, pois o aditivo foi efetivo numa concentraçâo permitida para uso em alimentos (Tabela 6).

O ácido tartárico nâo inibiu o crescimento e/ou a produçâo de aflatoxina no limite máximo permitido para o mesmo $(1,0 \%)$ (Tabela 7$)$, embora tenha havido uma disminuiçâo no diâmetro das colônias com o aumento da concentraçâo do aditivo.

O limite máximo de ácido cítrico permitido em alimentos é 1,0\%. Nesta concentraçâo todas as amostras se desemvolveram e produziram AT nas mesmas proporçôes observadas para as testemunhas, embora se observe uma disminuiçâo no diâmetro das colônias com o aumento da concentraçâo do aditivo (Tabela 8). Em meio acidificado com $\mathrm{HCl}$ a $20 \%$, ocorreu também esta reduçâo, sugerindo ser a acidez a responsável pela reduçâo observada. A produçâo de AT só foi reduzida e/ou inibida a 2,0\% do composto. Reiss (8) também testou este ácido e observou que a $0,5 \%$ do aditivo, em pâo de trigo, nâo houve produçâo de AT por Aspergillus parasiticus e a $0,75 \%$ ocorreu reduçâo no crescimento do fungo. Segundo o autor, os efeitos inibitớrios nâo foram ocasionados tâo somente pela acidez elevada no substrato; entretanto, de acordo com os resultados observados neste trabalho, pelos testes realizados em MCA acidificado com $\mathrm{HCl}$ a $20 \%$, observou-se que o $\mathrm{pH}$ pode interferir no crescimento e na produçâo de AT. E provável que estes aditivos dêem resultados eficientes se testados conjuntamente, dentro dos limites permitidos, agindo de forma sinérgica, proporcionando a inibiçâo do crescimento dos fungos e/ou produçâo de aflatoxỉras.

\section{REFERENCIAS}

1. Bothast, R.J. \& Fennel, D.G. (1969). A medium for rapid identification and enumeration of Aspergillus haves and related organisms. Mycologia 50-5.

2. Detroy, RW. et alii (1971). Aflatoxin and Related componds. In: Ciegen, A. ed. Microbiol toxins. Academic press, New York.

3. Goldblatt, LA. (1969). Aflatoxin Scientific background control and implications - Academic Press. New York.

4. Jay, J.M. (1978). Microbiotogja Moderna de los Alimentos, Zarogoza, Acribia.

5. Josefssop, B.G.E. \& Moller, T.E. (1977). Screening method of the detection of aflatoxin, ochratoxin, patulin, sterigmatocystin and zearalenona in cereals. Journa! Association Official Analytical Chemistry. 60: 1369.

6. Lin, M.T. \& Dianese, J.C. (1976). A Cooconut agar medium for rapid detection of aflatoxin Production by Aspergillas ssp. Phytopatology, 66: 1466-9

7. Raper, Kenneth B. \& Fennell, D.Z (1976). Cultivation. In: The Genus Aspergillus. Robert \& Publishing Malaber.

8. Reiss, O. (1971). Prevention of the formation of Mycotoxins in wheat bread by citric acid and lactic acid. Experientia, 32: 168-9.

9. Simåo, A.M. (1985). Aditivos para alimentos sob o aspecto toxicológico. Nobel, Sâo Paulo. 


\title{
FUNGOS ISOLADOS DO AR E DO PISO DE AMBIENTES FECHADOS DO HOSPITAL ESCOLA DA UNIVERSIDADE FEDERAL DE PERNAMBUCO, RECIFE, BRASIL - I
}

\author{
María da Glória de Barros \\ Departamento de Farmácia do Centro de \\ Ciências de Saúde da Universidade Federal \\ de Pernambuco Av. Artur de Sá S/N, \\ Cidade Universitária 50.740, \\ Recife-Pernambuco, Brasil.
}

\author{
M. A. Q. Cavalcanti, D. M. Massa Lima \\ e M. J. S. Fernandes \\ Departamento de Micología do Centro \\ de Ciências Biológicas da Universidade \\ Federal de Pernambuco Av. Artur de Sá, S/N, \\ Cidade Universitária 50.740, \\ Recife-Pernambuco, Brasil
}

Palabras clave: Hospital, Hongos ambientales, saprófitos y oportunistas.

Key words: Hospital, environment, saprophytic and opportunistic fungi.

\section{RESUMO}

Do ar e do piso de ambientes fechados do Hospital das Clínicas da Universidade Federal de Pernambuco, Recife, Brasil, foram isoladas 3.330 colônias de fungos que corresponden a 123 entidades taxonômicas pertencentes em sua maioria aos Asco-Deuteromycotina (95,3\%), estando os demais grupos pouco representados Zigomycotina $(5,6 \%)$ Basidiomycotina $(0,8 \%)$ e Micelia sterilia $(0,2 \%)$. Nâo houve diferença significativa entre o quantitativo de colônias detectadas durante o periodo de pluviosidade e estiagem. Observou-se maior número de colônias no piso em confronto com as detectadas no ar atmosférico. Os gêneros encontrados com mais freqüência e maior número de espécies foram Aspergillus, Penicillium $e$ Fusarium. Dentre os Hyphomycetes isolados 14 espécies sâo referidas como agentes etiológicos de micoses.

\section{RESUMEN}

[Hongos aislados del aire y del piso en ambientes confinados en el Hospital Escola Da Universidade Federal de Pemambuco, Recife, Brasii. I]

Del aire y del piso de ambientes confinados del "Hospital das Clinicas da Universidade Federal de Pemambuco, Recife, Brasil", fueron aisladas 3.330 colonias de hongos correspondientes a 123 entidades taxonómicas pertenecientes en su mayoría a los AscoDeuteromycotina $(95,3 \%)$, estando los demás gnt- pos escasamente representados Zigomycotina $(5,6 \%)$; Basidiomycotina $(0,8 \%)$ y Micelia sterilia $(0,2 \%)$. No hubo diferencias significativas entre la cantidad de colonias aisladas durante los periodos de pluviosidad y verano. Observándose el mayor número de colonias en el piso más que en aquellas aisladas del aire atmosférico. Los géneros encontrados con mayor frecuencia fueron Aspergillus, Penicillium y Fusarium. Entre los Hyphomycetes aislados, 14 especies son referidas como agentes etiológicos de micosis.

\section{SUMMARY}

[Fungi isolated from air and floor in closed environment in the Hospital Escola Da Universidade Federal de Per. nambuco, Recife, Brasil. I.]

The air and floor in hospital environment of the Clinical Hospital of the Federal university of Pernambuco, Recife, Brasil, were isolated 3.330 colonies corresponding to 123 taxonomic entities, most of them of Deuteromycotina group $(95,3 \%)$, being the other groups little represented Zygomycotina (5,6\%), Basidiomycotina $(0.8 \%)$ and Mycelia sterilia $(0.2 \%)$. There was no meaningful difference between the colonies isolated during the rainy and dry period. Grater number of colonies was observed from the material collected on the floor, rather than from the air. The most frequent genera and most number of species were: Aspergillus, Penicillium and Fusarium. Through Hyphomycetes isolated 14 species are refered as mycoses agents. 